\title{
Cristofania na Realidade Cosmoteândrica: cristologia de Raimon Panikkar e implicações para o Diálogo Inter- religioso e Intercultural
}

\author{
Christophany in the Cosmotheandric Reality: Raimon \\ Panikkar's Christology and its Implications for the \\ Intercultural and Interreligious Dialogues
}

\author{
RITA MACEDO GRASSI ${ }^{\mathrm{a}}$ \\ ROBERLEI PANASIEWICZ ${ }^{\mathrm{b}}$
}

\section{Resumo}

No mundo contemporâneo, religiões e culturas se entrelaçam continuamente. Destacamos cristianismo, hinduísmo e budismo com suas riquezas históricas e teológicas incomensuráveis. Seria possível articulá-las para benefício do humanum, da humanidade e do diálogo inter-religioso e intercultural? Raimon Panikkar (1918-2010) procurou enfrentar este desafio. De caráter bibliográfico, esta investigação se propõe destacar aspectos das suas intuições teológicas que estimulam relações dialogais. A noção hindu advaita (adualidade) o possibilitou reler algumas de suas experiências teológicas. Destacaremos sua concepção de Trindade, a realidade denominada cosmoteândrica e suas implicações para a cristologia, denominada de cristofania. Estas intuições despertam novos direcionamentos para o diálogo inter-religioso e intercultural.

Palavras-chave: Realidade Cosmoteândrica. Cristofania. Raimon Panikkar. Diálogo Interreligioso. Diálogo Intercultural.

\footnotetext{
a Pontifícia Universidade Católica de Minhas Gerais (PUC Minas), Belo Horizonte, MG, Brasil. Mestre em Ciências da Religião, e-mail: ritagrassi2010@gmail.com

b Pontifícia Universidade Católica de Minhas Gerais (PUC Minas), Belo Horizonte, MG, Brasil. Doutor em Ciências da Religião, e-mail: roberlei@pucminas.br
} 


\section{Abstract}

In the contemporary world, religions and cultures are mutually intertwined. We highlight Christianism, Hinduism and Budism and their incommensurable historical and theological richesses. Would it be possible to articulate them to the benefit of both the humanum and humanity? Raimon Panikkar (1918-2010) has faced this challenge. Of a bibliographical nature, this research intends to highlight aspects of his theological intuitions which stimulate dialogical relationships. The Hindu notion of advaita (aduality) has made it possible for him to reread some of his theological experiences. We highlight his conception of the Trinity, the cosmotheandric reality and its implications to the Christology, named Christofania. These intuitions awake new directions to the intercultural and interreligious dialogues.

Keywords: Cosmotheandric reality. Christophany. Raimon Panikkar. Interreligious Dialogue. Intercultural Dialogue.

\section{Introdução}

A teologia cristã traz em sua bagagem histórica riqueza inestimável. Tradição, textos sagrados, doutrinas, correntes teológicas se alinham, se desalinham e se articulam numa infinidade de debates e perspectivas que propiciam enriquecer sua trajetória e pertences que muitas vezes são inenarráveis e incomensuráveis. De modo diferente, porém, com a mesma beleza e riqueza, somente com tradição histórica mais ampla, se apresenta a teologia hindu. Duas potências em se tratando de reflexão, produção e partilha de construções teológicas. São heranças históricas disponíveis a todas as pessoas e instituições. Seria possível articulá-las em benefício do humanun, da humanidade e do estímulo a diálogos inter-religiosos e interculturais?

Raimon Panikkar (1918-2010), espanhol, filho de mãe católica e pai hindu, formou-se em filosofia e teologia, sacerdote católico e, também, residiu grande parte de sua vida na Índia, onde pôde dialogar com mestres do hinduísmo e do 
budismo, buscou, naturalmente, articular as riquezas destas tradições religiosas ${ }^{1}$. De personalidade forte, porém, extremamente dialógico, pôde reler os tratados de sua tradição religiosa desde outra perspectiva. Nos últimos anos, suas Obras Completas têm sido publicadas em vários idiomas. Estas obras retratam sua versatilidade filosófica e teológica e sua contribuição para diálogos interreligiosos e interculturais. A amplitude de possibilidades teóricas e práticas, voltadas para uma abordagem envolvendo aspectos da ortodoxia e da ortopraxia são possibilidades que se apresentam e sinalizam novas construções.

Este artigo, que teve como método teórico a pesquisa bibliográfica, se propõe a investigar aspectos da obra e das intuições de Raimon Panikkar com foco em sua compreensão cosmoteândrica da realidade, ou seja, a profunda relação e simultânea articulação entre Deus-Humano-Cosmos. Esta compreensão reflete a noção de advaita (adualidade) que também auxiliará a (re)pensar a Trindade e a cristologia, que ele denominará de cristofania ${ }^{2}$. Como ele chega a esta construção e quais as consequências, teóricas e práticas, desta elaboração? A busca desta resposta configura a proposta desta reflexão.

O caminho percorrido será apresentado em três partes. Primeiramente, será apresentada a compreensão teológica da Trindade cristã de Panikkar e como ela foi relida a partir da noção de advaita — adualidade —, própria da experiência com o hinduísmo. Esta noção o inspira a expandir sua visão da relação trinitária cristã e a perceber características triádicas do divino, do humano e do cosmos. Experiência que denominou de "realidade cosmoteândrica". Num segundo

\footnotetext{
${ }^{1}$ Nascido em Barcelona num lar cristão-hindu, percorreu o caminho do catolicismo desde a infância, por influência de sua mãe catalã e católica; mas sempre em contato com o hinduísmo e sua tradição, através de seu pai, que era indiano e hindu. Doutorou-se em Filosofia (1946), em Química (1958) e em Teologia (1961), lecionou durante muitos anos na Universidade de Harvard (como Professor Visitante) e no Departamento de Estudos Religiosos da Universidade de Santa Bárbara, além de ter dado cursos e palestras em universidades ao redor do mundo.

2 Panikkar (2005) prefere traduzir a palavra advaita por adualidade (e não por não-dualidade, como está na maior parte das traduções), pois não se trata de rejeitar ou omitir a dualidade, mas da sua inexistência.
} 
momento, discutiremos as implicações desta noção à sua concepção de cristologia, a qual o levou a desenvolver uma nova expressão que nomeou de "cristofania". Por fim, serão apresentadas as correlações e possibilidades que emergem destas categorias para o diálogo inter-religioso e intercultural.

\section{Mútua implicação entre Trindade e Realidade Cosmoteândrica}

O convívio e o mergulho existencial na teologia e nas crenças do hinduísmo possibilitaram Panikkar a atingir profundidade tamanha que podemos apreendêla através de sua afirmação: "eu parti cristão, me descobri hindu e me tornei budista, sem jamais ter deixado de ser cristão. Em meu retorno, me descobri um melhor cristão" (PANIKKAR, 2012, p. 121). Perspectiva que se assemelha ao incansável peregrino que a cada dia marcha em busca de um sentido maior para a vida e para a realização humana, mesmo sem ter a direção definida. Para o peregrino, "o caminho se faz ao caminhar", a clareza vem com os encontros e desencontros com pessoas e tradições religiosas e culturais.

Em Panikkar, a marca desta peregrinação encontra-se, em grande parte, envolta à noção de advaita, selo de sua identidade existencial e que permeia sua reflexão e prática místico-teológicas. Advaita como uma maneira de ser e de estar no mundo de forma adual, ou seja, perceber tudo a sua volta com ausência de dualidade³. Em entrevista dada a José Luis Meza Rueda (2009), Panikkar afirma que "o princípio advaita não é não-dualismo, mas adualismo. O primeiro refere-se ao princípio da não-contradição e isto eu respeito. Em mudança, o segundo, refere-se à ausência de dualidade". Implica dizer que tudo está em relação e não em contradição, mesmo podendo haver contradições. Claridade e escuridão ou

\footnotetext{
${ }^{3}$ Para maior conhecimento do termo advaita ver: GRASSI, R. M. Uma peregrinação advaita ao encontro do outro: o diálogo inter-religioso na obra de Raimon Panikkar. Belo Horizonte: PUC Minas, 2019.
} 
luz e sombra, por exemplo, coexistem de forma distintas e articuladas. Elas não se contradizem, mas se relacionam. $E$, ainda, uma fortalece a existência da outra sem negá-la. Este princípio advaita possibilitará a Panikkar reler a teologia cristã desde outra ótica. Assim, qual será sua maneira de compreender a Trindade cristã? Possibilitará, também, a uma outra interpretação da relação Deus-MundoHumano? A explicitação destas perguntas caracteriza o objetivo deste primeiro tópico.

\subsection{Concepção panikkariana de Trindade}

A Trindade cristã, ao longo da história do cristianismo, tem desafiado e sempre convida os teólogos cristãos à constante reflexão. Riscos de modalismos (um Deus que se revela em três modos ou com máscaras distintas) ou de triteísmos (três pessoas e três substâncias distintas) perpassam este debate. Panikkar compreende que há profunda relação entre o Ser e Deus e enfrenta este desafio dizendo que, "a Trindade é, efetivamente, o mistério real da Unidade, pois a verdadeira unidade é trinitária. Por esta razão não há, falando com rigor, um Simesmo em sentido reflexivo. O Si-mesmo do Pai é o Filho, seu em-Si é o Espírito". (PANIKKAR, 2016c, p. 164).

Esta relação de subsistência entre Pai-Filho-Espírito, proclamada pela Tradição cristã, perpassa a compreensão de Panikkar. Entretanto, via o princípio advaita, ele relê o problema intratrinitário afirmando que, "se o Pai e o Filho não são dois, muito menos são um: o Espírito os une e os distingue ao mesmo tempo. Ele é o vínculo de unidade; o nós no meio, ou melhor, no íntimo" (PANIKKAR, 2016c, p. 145).

O Espírito promove a integração trinitária como, também, nos disponibiliza a entrarmos nesta contemplação relacional. Assim, "a Trindade não é doutrina revelada, mas experiência vivida. Buscá-la exegeticamente é um erro" (PANIKKAR, 2016c, p. 145). Ele quer trazer a experiência da Trindade ao cotidiano dos cristãos. Mais do que promover discussões especulativas sobre o mistério da 
Trindade, o importante seria possibilitar experiências místicas em que o silêncio contemplativo se torna tanto erudito, quanto linguagem verbal. A mística tornase, para o autor, o "terceiro olho" que possibilita ver desde uma outra perspectiva 4 .

Segundo Cousins, na história da teologia Trinitária, existe duas tendências: a que restringe o evento trinitário à "revelação em Cristo e ao trabalho santificado do Espírito na Igreja"; e aquela que "universaliza a Trindade à toda a expansão do universo, na sua criação e história". Panikkar claramente se situa nesta segunda tendência, que tem como precursores "a doutrina do vestígio do Agostianismo medieval”, "a doutrina Trinitária da criação" da patrística grega e "a doutrina da apropriação dos Santos Padres e dos escolásticos" (COUSINS, 1998, p. 85). Para ele, Panikkar se insere e, ao mesmo tempo, ultrapassa cada uma dessas tendências, trazendo ares inovadores por meio da "intuição advaita".

Entretanto, como Panikkar pensa a Trindade? Inspirando-se, principalmente, na patrística grega e em São Boaventura, ele define a Trindade como sendo:

a) o Pai, a dimensão apofática ("Deus é Silêncio"), origem e fonte de tudo o que há. Quem gera o Filho e, ao mesmo tempo, passa a existir através dele. "O Pai não tem ser: o Filho é seu ser";

b) o Filho, a dimensão personalista, manifesta na figura do Cristo, que seria o próprio Deus, "a Pessoa Divina, o Senhor", o "mediador", "só se chega ao Pai, através do Filho", pois é com ele que se entra em relação;

c) o Espírito, a dimensão imanente (ou mística), que permeia tanto o Pai quanto o Filho, os conecta e ao mesmo tempo os diferencia. O Espírito é o amor que flui entre o Pai e o Filho (PANIKKAR, 2011, s/p.).

\footnotetext{
${ }^{4}$ A visão do "Todo no Concreto" é, para o autor, precisamente a visão do terceiro olho, pois não enxerga somente uma coisa ("monismo") e depois a outra ("dualismo"), mas a um só tempo, e com a ajuda dos dois outros olhos, a relação harmoniosa que há em tudo o que existe (adualismo), inclusive nos seres humanos. Este conceito é utilizado por Panikkar, tendo como base a "escola medieval dos vitorinos", mais precisamente da teoria dos "três olhos: oculus carnis, oculus rationis e oculus fidei" ou "olho da contemplação", do "teólogo e místico" Ricardo San Victor (PÉREZ PRIETO, 2008).
} 
Para além da reflexão teológica cristã, Panikkar tem influência de outras perspectivas, em especial, do hinduísmo advaita e do budismo que, segundo Cousins, são "fundamentais para compreender a concepção trinitária de Panikkar" (COUSINS, 1998, p. 73). Dentre as influências do hinduísmo, D’Sa e Prieto citam, respectivamente, os conceitos de trimūrti, de rta e a "tríade Sat-CitAnanda" ${ }^{5}$. D'Sa (2008b) relaciona rta com o que Panikkar denominou de ontonomia, ou seja, um princípio ontológico, onde a identidade de cada parte do todo reflete o próprio todo, em uma relação de "interindependência" que os torna tão "intimamente conectados" que passam a ser uma só realidade, sem divisões, mas sem, no entanto, ignorar a unicidade de cada parte.

O conceito budista que teria influenciado a visão trinitária de Panikkar, de acordo com Prieto (2008), teria sido o princípio de pratityasamutpāda, ou seja, a afirmação de "que nada existe por si mesmo, que nada tem em si mesmo o fundamento de sua própria existência, ao contrário, tudo está condicionado a tudo no ciclo da existência" (PANIKKAR, 2015, p. 460). Panikkar utiliza o termo para nomear a dinâmica de "relação e dependência" que, de fato, "substancializa" o ser, o qual, sem isso, de acordo com a linguagem budista, seria "vazio" (śūnya). Esse princípio é um "equivalente homeomórfico" da "perichōrēsis trinitária" e do "karma cósmico hindu" e os três serviram de inspiração para o seu conceito de "interindependência" (PANIKKAR, 2013, p. 284).

Para Panikkar, as Pessoas da Trindade não podem ser vistas como separadas por estarem em relação pericorética, ou seja, de "interpenetração". Ele a denominará de "relacionalidade radical", onde "o Pai não existe sem o Filho e ambos não existem sem o Espírito Santo" de cada 'Pessoa' é preservada sem, de nenhuma forma, diluir sua

\footnotetext{
${ }^{5} \mathrm{~A}$ "tríade Sat-cit-ananda" refere-se à natureza de Brahman para o Vedanta advaita de Śańkara, onde Sat é "pura existência" e poderia relacionar-se ao Pai; Cit é a consciência, o Filho; e Ananda, a felicidade plena, o amor, o Espírito. E todos eles são a um só tempo um: Sat-cit-ananda (pura existência consciente e plena) (D'SA, 2008; PRIETO, 2008).

${ }^{6} \mathrm{O}$ termo perichōrēsis foi utilizado pela teologia, inicialmente, para se referir à cristologia como "unidade da natureza humana e divina em Cristo" (PRIETO, 2008).
} 
interindependência. Em outras palavras, há uma relação advaita entre as três Pessoas" (D'SA, 2008b, p. 5).

A partir desse princípio de "interindependência" ou de "relacionalidade radical”, que compõe a Trindade cristã, o Espírito, teria como função articular o "nós" da relação, em que, "o Pai e o Filho não são dois, muito menos são um". Para Panikkar, a visão trinitária seria um "equivalente homeomórfico" do advaita, podendo ser estendida a outras compreensões religiosas e filosóficas sobre a realidade, sem ser uma exclusividade cristã̃. A intuição advaita "está intimamente ligada à, quase universal, compreensão trinitária da humanidade" (PANIKKAR, 2013, p. 212). A visão tripartida da realidade divina, humana e cósmica caracteriza a maneira humana de concebê-las. "Aparece em uma visão triádica tanto da realidade (o divino, o humano e o cósmico) como do homem (corpo, alma, espírito) e do mundo (espaço, tempo e matéria)" (PANIKKAR, 2016c, p. 173). Tais influências fizeram com que Panikkar começasse a conceber a Trindade como uma espécie de "invariante cultural” e, portanto, humana, presente nas tradições religiosas. " $\mathrm{Na}$ experiência trinitária, encontram-se em profundidade e fecundação mútua as diferentes atitudes espirituais, sem forçar nem violentar as particularidades fundamentais das distintas tradições religiosas" 8 (PANIKKAR, 2011).

Segundo Pikaza (2008), "Panikkar foi, de alguma maneira, o primeiro que, de um modo consequente, situou o tema do Deus trinitário no centro do diálogo do cristianismo com as religiões orientais [...]". No entanto, ressalta que:

\footnotetext{
7 A trimūrti seria, em linguagem panikkariana, o "equivalente homeomórfico" à Trindade no Hinduísmo, composta pelas deidades Brahma, Vișnu e Śiva. Em que Brahman representa "o Absoluto", Viṣnu "o mantenedor" e Śiva "o destruidor do universo" (PANIKKAR, 2017, p. 414).

${ }^{8}$ Prieto questiona este "invariante cultural", pois apesar de parecer "um magnífico ponto de partida para o diálogo inter-religioso" é "polêmico" e discutível (PRIETO, 2008). Rudolf Von Sinner também faz críticas ao dizer que "Panikkar se afastou da revelação da trindade ao conceber, numa troca com - Advaita-Vedanta hinduísta e com o Pratityasamutpada budista, uma 'trindade' como figura que retoma essa revelação (de Cristo), mas abstrai dela" (VON SINNER, 2004, p. 55).
} 
Isto, que pode parecer uma novidade contrária à tradição cristã, constitui um momento básico da tradição teológica da Igreja, tal como a formularam, sobretudo, os grandes teólogos alexandrinos, de Orígenes a São Cirilo. Para eles, a Trindade era antes de tudo a vinculação do Logos cósmico (mundo) com o Logos humano (Cristo) e divino (Deus). Nessa linha situa-se, de algum modo, Panikkar (PIKAZA, 2008, tradução nossa).

Ele procura, assim, articular a teologia de Panikkar com os primórdios da fé cristã apontando para sua Trindade Radical. "Esta noção da Trindade radical é fruto do que temos chamado de uma experiência teantropocósmica que, por respeito à tradição e para evitar cacofonia, temos denominado cosmoteândrica" (PANIKKAR, 2016c, p. 175). A Trindade radical é, portanto, a Realidade Cosmoteândrica, em que Deus, Humano e Cosmos estão em profunda unidade relacional. Como compreender esta Realidade Cosmoteândrica?

\subsection{A realidade cosmoteândrica}

A realidade teândrica busca articular de forma adual Deus e o ser humano, não permitindo que sejam considerados de forma isolada e em descontinuidade. O Cosmos também passa a integrar esta realidade, porém, agora, maieuticamente, compreendido como existente e como sempre presente nesta relação. Assim, nasce a visão cosmoteândrica de Panikkar: de uma necessidade do mundo atual de enxergar a realidade por inteiro e colocar em prática a visão trinitária tendo como base uma perspectiva onde o cosmos, o ser humano e o divino estejam relacionados de forma pericorética e "interindependente", em "uma ordem ontonômica".

Segundo a teóloga indiana Clemens Mendonça (2008), a dimensão cósmica seria o primeiro nível da nossa experiência da realidade, a dimensão “quantificável, perceptível e objetificável”. Prieto complementa essa ideia, já em linguagem panikkariana, ao afirmar que "o cosmos é o elemento material da realidade cosmoteândrica, a energia; corresponderia na Trindade cristã ao Espírito Santo, ainda que possa parecer um paradoxo para alguns pela presumida 
contraposição (dualista) entre o espírito e a matéria" (PRIETO, 2008). Nesta linha de Prieto, mas trazendo para o seu "paradigma ecológico", Leonardo Boff diz que:

A casa-hábitat-oikos, na verdade, é feita de seres vivos, matéria, energia, corpos e forças em permanente relação. [...] Deste jogo divino de relações o universo inteiro se deriva, feito à imagem e semelhança da Trindade. O cosmos se apresenta inter-relacionado como é, porque resulta do inter-relacionamento trinitário (BOFF, 1996, p. 19).

Por estarem inter-relacionados que tanto Panikkar quanto Boff chamam a atenção para a ação do ser humano no mundo. Panikkar (2011) fala da escuta da natureza e nomeia tal atitude de ecosofia, ou seja, "sabedoria da terra". Nela, o ser humano deve ser o grande aprendiz. Caberia, aqui, o desenvolvimento de uma "espiritualidade secular", ou de uma "secularidade sagrada", com teor soteriológico. Trata-se de uma visão de mundo que une o espírito e a matéria, o sagrado e o profano, mais uma vez, de forma adual. Perspectiva em que o ser humano se encontra intrinsecamente conectado com o universo, com o cosmos e com a natureza de forma integral e que descobre sua "salvação" nessa relação. Jyri Komulainen ensaia uma síntese do que seria essa dimensão cósmica para Panikkar:

A dimensão cósmica significa que todos os seres não apenas 'estão no Mundo', mas também 'compartilham de sua secularidade'. Estar no mundo significa que tudo o que existe tem uma relação constitutiva com a matéria e a energia e, também, com o tempo e o espaço. [...] Panikkar sugere que ocorreu uma mutação significativa na espiritualidade, que revelou 'a sacralidade do secular'. A visão cosmoteândrica representa este tipo de espiritualidade, porque não 'abandona nem o tempo, nem o espaço', mas dá lugar a eles (KOMULAINEN, 2006, p. 295, tradução nossa).

A dimensão humana é a própria consciência que compreende o mundo como real, é a consciência que "descobre" a rede de relações que compõem a totalidade. Para Panikkar (2015), a consciência humana passou por três momentos

\footnotetext{
${ }^{9}$ Identificado por Baptista (2011) como "equivalente" à visão cosmoteândrica de Panikkar.
} 
kairológicos": o momento primordial ou ecumênico; o momento humanístico ou econômico; e o momento da nova inocência, o momento cosmoteândrico, que ele também chamará de momento católico, em outros lugares de sua obra. Segundo Rueda, Panikkar enxerga o ser humano como uma "realidade teantropocósmica", ou seja, é a um só tempo cósmico, humano e divino; “é corpo, é alma e é espírito, em uma unidade irredutível, diferenciada e inseparável" (MEZA RUEDA, 2009, p. 69). Seria, em outras palavras, uma síntese do "mistério trinitário", integrando-se à "realidade total, participando da perichōrēsis de todas as coisas e sendo ele próprio uma dessas relações" e, ainda, "a pátria do homem é a Terra material; ou, melhor, a Terra é a mãe do homem, mas esse é também filho do Céu, seu Pai, em harmonia advaita" (PANIKKAR, 2011).

Esta harmonia natural entre "céu" e "terra" convoca o ser humano a se responsabilizar com o cuidado e com a transformação do mundo. O ser humano seria, então, um cocriador da realidade, que está em constante movimento ("creatio continua") 10. A dimensão divina, para Panikkar, assim como o Pai, é fonte e origem da Realidade que perpassa as três dimensões e, a um só tempo, as transcende. Trata-se de um nível mais profundo da consciência humana em busca da "própria identidade". "A divindade é o símbolo do que transcende ao ser humano e, ao mesmo tempo, do que está escondido em sua essência mais profunda" (PANIKKAR, 2011). Apesar disso, o ser humano nunca pode de fato apreendê-la completamente, restando sempre algo a descobrir.

Panikkar ao buscar universalizar sua percepção do divino e abri-lo para uma perspectiva mais pluralista e de propensão para o diálogo inter-religioso, coloca a figura de Cristo como sendo o símbolo que melhor traduz sua "espiritualidade cosmoteândrica".

\footnotetext{
$10 \mathrm{O}$ conceito de cocriação perpassa algumas obras como as de Adolphe Gesché e Andrés Torres Queiruga. Seria um despertar na "consciência humana" da "contemplação do amor do Criador às criaturas e de sua compreensão de ser 'imagem e semelhança' de Deus"; dessa forma: "ser cocriador significa ser corresponsável com Deus por toda a criação" (PANASIEWICZ, 2009, p. 175). Juan Luis Segundo (1995) também usou o termo "co-criador", como consequência do amor e do desapego de Deus ao "deixar sua criação inteira condicionada a um 'sim' ou a um 'não'" dos seres humanos.
} 
Um Deus cuja natureza é pura relação. [...] Tudo é relação [...] inclui Deus, o mundo, o homem também. [...] Toda a Realidade é esta Trindade do divino, do cósmico e do humano [...]. [Ainda que] não haja uma mistura entre o humano, o cósmico e o divino, tampouco podem ser separados entre si. Esta espiritualidade cosmoteândrica é a que tento viver e, para mim, Cristo é o símbolo (PANIKKAR apud PRIETO, 2008, tradução nossa).

Cristo seria, portanto, para Panikkar, a síntese da "Trindade radical", da relação entre as três dimensões da realidade, o ápice de sua compreensão trinitária. Como Panikkar compreende a realidade cosmoteândrica na encarnação de Jesus Cristo?

\section{A Cristofania}

$\mathrm{Na}$ tradição cristã, o tema da cristologia perpassa gerações e segue desafiando a reflexão dos teólogos. Num mundo marcado por vários pluralismos, em especial, pelo pluralismo religioso, pensar a encarnação de Jesus Cristo como único evento salvífico para a humanidade incomoda mesmo mentes mais conservadoras. É possível afirmar a identidade cristã sem negar outras identidades religiosas? Como ocorrido na compreensão da Trindade, Panikkar afirma que é necessário ir além do intelecto e ter uma experiência cristológica, ou seja, compreender a articulação entre vida, morte e ressurreição de Jesus Cristo. Isto permitirá uma imersão no próprio sentido de advaita e a vivenciar a cristofania. "A substituição da palavra 'Cristologia' por Cristofania' não significa que estamos esquecendo o logos", mas buscando "estender e aprofundar os campos até hoje inexplorados e propor novas perspectivas" (PANIKKAR, 2016a, p. 114). Cristofania refere-se a uma leitura experiencial criativa e criadora de intuições e verdades que perpassam a revelação acontecida em Jesus Cristo. Trindade, Realidade Cosmoteândrica e Cristofania são percepções essenciais da experiência teológica e mística de Panikkar. Nas palavras de D’Sa, 
nossa era tem problemas com todos os três centros da realidade: Deus, o Mundo, e o Homem. A ciência ignora Deus; o Homem não se importa com o mundo; e agora o mundo está contra-atacando. E nossas soluções são, no melhor dos casos, fragmentadas e, no pior, cosméticas. É nesse contexto que Christophany, The Fullness of Man (Cristofania, a plenitude do Homem) empreende uma revisão em larga escala da nossa compreensão desses três centros; essa plenitude deve ser experienciada, se for, no nível ādhyātmic. É uma declaração de missão para o novo milênio - uma declaração que pode ser compreendida somente quando lida com o terceiro olho! (D'SA, 2008a, p. 7, tradução nossa). ${ }^{11}$

O princípio advaita permite compreender a figura de Cristo estabelecendo profunda harmonia entre transcendente e imanente, entre Deus e humano, sem distância ou sem desequilíbrio. Ele é a manifestação da Trindade radical, "unidade não-dualista entre o divino e o humano", que seria o "mistério teândrico do Oriente”. Para Panikkar, “o ser humano, também, constitui uma unidade nãodualista entre o espírito e o corpo" (PANIKKAR, 2016b, p.274). Ele resume essa ideia da seguinte forma:

O Filho do Homem é o Filho de Deus. Não é que Deus esteja aqui, o Homem lá, e a Terra em algum lugar abaixo [...] [Jesus] viveu a plenitude do humano [...] ao passo que sabia que é a obrigação de cada um de nós assumir nossas responsabilidades para que o esforço comum alcance uma justiça maior. Mas, essa plenitude humana, também inclui a participação no divino - relembrando, assim, o que somos chamados a nos tornarmos (PANIKKAR, 2016a, p.280, tradução nossa).

Panikkar chama a atenção para o papel de Jesus Cristo como um modelo para a humanidade do que seria, de fato, essa plenitude, recordando a função cocriadora e participativa do ser humano com o divino da visão cosmoteândrica. Será a partir dessa concepção que ele afirmará que "todo ser é uma cristofania, uma manifestação de Cristo" (PANIKKAR, 2011). Esse potencial estaria presente em todos os seres em uma relação teândrica e adualista entre o divino, o humano e o material.

\footnotetext{
${ }^{11}$ A palavra sânscrita ādhyātmic refere-se à "qualificação aplicada à vida espiritual que nos transporta ao conhecimento do Self (ätma), à experiência interior que corresponde à dimensão mais profunda do nosso ser". (PANIKKAR, 2016a, p.305).
} 
O termo teandrismo indica com clareza suficiente estes dois elementos de toda espiritualidade: o elemento humano, que serve de ponto de partida, e o fator transhumano, que o vivifica a partir do seu interior e é a sua consequência transcendente. Essa palavra é na realidade cristã, mas não é uma noção exclusiva da tradição cristã. Ao contrário, está presente como o fim ao qual tende a consciência religiosa da humanidade e, também, como a interpretação mais adequada da experiência mística (PANIKKAR, 2011, tradução nossa).

Potencialidade humana e plenitude divina reunidas na figura de Jesus Cristo. Esta perspectiva teândrica e adualista pode ser percebida na interpretação teológica de Jesus e de Cristo em que Amaladoss distingue para avançar ao dizer que "Jesus é Cristo, mas Cristo é mais do que Jesus" (AMALADOSS, 1993, p. 100). Cristo é revelado na historicidade de Jesus, porém, a totalidade do Cristo não se restringe ao homem Jesus de Nazaré.

Nesta mesma trilha interpretativa, Panikkar afirma que "Jesus é Cristo, mas Cristo não pode ser identificado completamente com Jesus de Nazaré." (PANIKKAR, 2016a, p. 249). A identificação de Jesus de Nazaré com o Cristo é a base da doutrina cristã, entretanto, "Cristo não é um monopólio cristão" (PANIKKAR, 2016a, p. 253). Cristo está para além do que a tradição cristã captou e expressou em suas Narrativas Sagradas. Isto pode ser compreendido na expressão: "Cristo está em todo irmão que sofre, e Jesus de Nazaré não está lá" (PANIKKAR apud MEZA RUEDA, 2012 p. 126). A perspectiva cristofânica acentua a presença crística e pode ser lida na passagem do Segundo Testamento em que Jesus declara: "[...] na medida em que fizestes a um destes meus irmãos, mais pequeninos, a mim o fizestes" (Mt. 25, 40) $)^{12}$.

D’Sa entende que a perspectiva que delineia Panikkar a fazer essa distinção entre Jesus e Cristo passa, primordialmente, por sua visão da interculturalidade e da inter-religiosidade. E acrescenta que:

\footnotetext{
${ }^{12}$ Claude Geffré faz distinção entre "valores implicitamente cristãos", que derivam do cristianismo histórico, e "valores crísticos", que derivam de Jesus Cristo. Ver: PANASIEWICZ, 2010, p. 135-155.
} 
Seu interesse principal nunca foi a história, porque a história não é a realidade inteira. É apenas um aspecto da realidade. Além disso, ele é consciente do desenvolvimento unilateral da consciência histórica no mundo ocidental. [...] Na verdade, Cristo é apenas a abordagem e a experiência Cristãs do Mistério que está presente em todas as religiões, revelações e movimentos em direção à [...] verdade, à bondade e à beleza (D'SA, 2008a, p. 2, tradução nossa).

Panikkar não utiliza a história como uma metodologia em sua obra, mas se ocupa em fazer críticas e analisar de que forma o pensamento ocidental tem sido condicionado a ela. E, no caso específico de Jesus, ele afirma que:

Atribuir a esse homem tudo o que o credo cristão afirma sobre Jesus foi um dos problemas cruciais da teologia cristã: como pode esse homem fazer parte da Trindade, como pôde existir antes de Abraão, como é que foi o Messias, o redentor de todo o mundo, o alpha e o ômega e, portanto, o único salvador, o único caminho e o único nome? (PANIKKAR, 2015, p. 118).

Estas reflexões em nada diminuem o homem Jesus, somente procuram, ao distinguir, colocar em diálogo a singularidade da natureza humana e divina de Jesus Cristo. A excepcionalidade deste Jesus levou Leonardo Boff a concluir que “humano assim como Jesus só Deus mesmo" (BOFF, 2017). Kasper dirá que "este Jesus de Nazaré, único, insubstituível é, simultaneamente, o Cristo enviado por Deus, isto é, o Messias ungido pelo Espírito, à salvação do mundo, à plenitude escatológica da história" (KASPER, 1984, p. 14). Vida, morte e ressurreição de Jesus Cristo ou, nesta perspectiva, vida e morte de Jesus e ressurreição e exaltação de Cristo, expressam o conteúdo da fé cristã e ensaiam a cristofania.

Este Jesus de Nazaré, único, insubstituível, é simultaneamente o Cristo enviado por Deus, isto é, o Messias ungido pelo Espírito, a salvação do mundo, a plenitude escatológica da história.

Uma Cristofania pluralista desafia a reductio ad unum (redução à uniformidade), considerando-a uma exigência do logos intelectual - enquanto a Cristofania, propriamente dita, não é redutível ao logos. Cristofania inclui pneuma, espírito. Os dois são inseparáveis e irredutíveis. [...] E isso, como já vimos, requer a visão mística, o terceiro olho (PANIKKAR, 2016a, p. 267, tradução nossa). 
A Cristofania propõe um mergulho na própria identidade crística, que precisa ser experimentada e não, apenas, racionalizada. O intelecto não seria suficiente para uma total compreensão desse tipo de "cristologia", que não se restringe ao logos.

Panikkar pensa a cristologia desde outra lógica, ou seja, na articulação e diálogo com o hinduísmo. Para ele, "não significa que esta realidade [Cristo] tenha muitos nomes, como se pudesse haver uma realidade fora do nome. Esta realidade é muitos nomes [...] Não obstante cada nome expressa, por assim dizer, o mistério indiviso". E segue afirmando que, "assim como não pode haver uma pluralidade de deuses [...] não pode haver uma pluralidade de Cristos". (PANIKKAR, 1994, p. 28-29). Sua cristofania diz da manifestação de Cristo à consciência humana, mas através do viés da sabedoria e da mística e, não somente, pela racionalidade. Neste sentido, não se prende à exegese bíblica, mas se abre ao diálogo com as demais tradições religiosas. Para além dessa noção, é importante destacar, também, a dimensão da corporeidade neste processo da manifestação crística.

A cristofania transcende a pessoa de Jesus. Para Prieto, ela busca a articulação de cristologias aparentemente opostas: a tradicional cristologia descendente e a moderna cristologia ascendente se articulando desde o interior; uma cristofania desde o centro em que o infinito e o finito, o material e o espiritual, o cósmico e o divino, se encontram (PRIETO apud MEZA RUEDA, 2012, p. 133-134). E, para além destas articulações, Rueda demarca que a cristofania deve também fazer referência ao Espírito (Pneuma) e não somente ao Logos (MEZA RUEDA, 2012, p. 133-134). Roger Haight concluirá dizendo que

uma cristologia do Espírito, ao reconhecer que o Espírito é operativo externamente à fé cristã, está aberta a outras mediações de Deus. O Espírito se expande, e não é necessário pensar que Deus como Espírito possa encarnar-se apenas uma vez na história (HAIGHT, 2003, p. 523). 
Panikkar parte da noção de Trindade cristã, por sua formação teológica, entretanto, a partir do contato com outras tradições religiosas, reinterpreta não somente a Trindade, mas toda a relação existente entre Deus-Humano-Cosmos. Isto o possibilita novas construções teológicas. Agora, como esta realidade cosmoteândrica, que provoca releituras da Trindade e da Cristologia, possibilita Panikkar a compreender a realidade plural e a apontar novas perspectivas para o diálogo inter-religioso?

\section{Pluralismo e implicações para o Diálogo Inter-religioso}

A realidade se manifesta plural. A consciência e a clareza da pluralidade se ampliam na medida em que avançam os meios de comunicação e as possibilidades de encontro entre culturas. Perceber que há "um outro" para além das "minhas" fronteiras históricas e culturais sinaliza que há vida e outra compreensão de mundo para além dos horizontes e padrões de conhecimentos estabelecidos por uma cultura. O pluralismo sinaliza pluralidade, mas vai além. Para Panikkar, pluralismo significa pluralidade (diferença), pluriformidade (variedade) e harmonia inalcançável (diversidade) (PANIKKAR, 2016b, p. 48-49). Pluralismo diz da beleza, da riqueza e da contradição da realidade. Ele não se fixa no fato, mas envolve a diferença, a variedade e a diversidade buscando interpretá-las.

Diferença, variedade e diversidade se interpenetram na realidade cotidiana e convocam a consciência pluralista a responder a estas demandas e a construir respostas que estimulem o convívio. Respostas monistas e fundamentalistas podem inflamar ondas de violência e práticas pouco ou nada dialogáveis. Esta visão pluralista implica estar imerso na experiência do outro para poder compreender a sua forma de pensar e de agir, e, ainda mais, ter a consciência de não julgar a partir dos próprios "mitos", mas entender que cada experiência é única e não tem como ser absolutizada. Trata-se de uma "relatividade radical" (diferente do relativismo), como forma de enxergar todas as experiências humanas e que "[... ] está baseada na confiança no outro, ainda que eu possa não 
o compreender e, do meu ponto-de-vista, tenha que dizer que ele esteja errado. O pluralismo não absolutiza o erro, porque também não absolutiza a verdade" (PANIKKAR, 1979, p. 102). Isto suscita uma "confiança cósmica" de que nenhuma compreensão, por melhor que seja, dará conta de enxergar toda a verdade. Cada um tem uma percepção parcial do que seria o Mistério último da existência.

Panikkar foi criticado por vários teólogos cristãos, como Knitter e Dupuis. Entretanto, sua visão pluralista não pode ser analisada a partir do paradigma pluralista da Teologia do Pluralismo Religioso, mas como atitude pluralista ${ }^{13}$. Enquanto os paradigmas apontam para uma forma de pensar a realidade, sua perspectiva aponta para uma forma de experimentar a realidade. As duas abordagens são fundamentais tanto para a Teologia do Pluralismo Religioso quanto para o Diálogo Inter-Religioso. Porém, devem ser analisadas de maneira diferenciada. Em suas palavras, "o pluralismo inerente à intuição advaita não é um super-sistema, mas uma atitude" (PANIKKAR, 2013, p. 24). A "intuição advaita" consiste justamente em perceber "a beleza da unicidade" na diversidade, sem buscar uma "universalidade" ou um "princípio absoluto".

Para Panikkar, o pluralismo refere-se a uma experiência em que, mais uma vez, é preciso ir além do intelecto e da busca de um pensamento que pretenda unificar ou uniformizar tudo. Trata-se de uma atitude que, em sua expressão, refere-se ao "equivalente homeomórfico" à experiência advaita, realidade que compõe sua visão trinitária e cosmoteândrica.

Duas metáforas são bastante utilizadas por Panikkar para ilustrar o que ele chama de atitude pluralista. Uma é a estória do elefante em um quarto com seis deficientes visuais, onde cada um toca em uma parte do animal e acredita que $o$ elefante resuma-se àquela parte tocada. Por exemplo, a pessoa que toca nos dentes, acredita tratar-se de um objeto de marfim, a que toca na pata, acha que é um poste ou um tronco de árvore. Mas, ninguém conhece, de fato, o todo, ou

\footnotetext{
${ }_{13}$ Para compreensão os paradigmas da Teologia do Pluralismo Religioso, ver: TEIXEIRA, 2012; HAIGHT, 2003; VIGIL, 2006; KNITTER, 2009.
} 
seja, que se trata de um elefante. A atitude pluralista seria o reconhecimento de que somos capazes de apreender, apenas, uma parte do mistério que envolve a realidade e aceitar que outras pessoas apreendem outros pedaços, outras nuances, sentem outras texturas e outros relevos. O problema está quando acreditamos ser os detentores do conhecimento sobre esse "mistério". Para Prabhu,

em nenhum outro lugar o conto do elefante e dos seis homens cegos aplica-se tão apropriadamente quanto no caso de Panikkar. Não somente haverá diversas interpretações, mas dificilmente qualquer pessoa, inclusive o próprio Panikkar, possa fornecer uma visão do 'elefante inteiro' (PRABHU, 1996, p. 4, tradução nossa).

Outra, é a "metáfora da janela", onde cada um de nós olha através de uma janela (religião), cujo vidro é tão transparente, que nem nos damos conta de que se trata apenas de uma janela. E, se dermos um passo para trás, veremos que existem muitas janelas e pessoas diferentes olhando através das mesmas. Reconhecemos, então, que a nossa perspectiva é uma das possíveis visões daquilo que está para além da janela, que vai além do que a nossa visão alcança. Talvez (mas, não necessariamente), nos leve ao tal "vazio" ou "nada", que Panikkar acredita ser o "espaço comum", onde essas diferentes perspectivas pudessem se encontrar. Em suas palavras:

[...] estou totalmente convencido de que nem o meu ego, nem todos os cristãos ou, nem mesmo todos os meus colegas seres humanos, irão jamais esgotar o conhecimento de tal Mistério. Eu descubro, ao mesmo tempo, que há outras pessoas, outras visões de mundo, outras religiões (outras janelas). Eu posso nem ser capaz de formular como elas experimentam a realidade, ao ignorar os parâmetros nos quais encaixam suas respectivas experiências. Não posso dizer que elas afirmam, em palavras diferentes, a 'mesma coisa' que eu. Frequentemente, nem mesmo compreendo a sua fala. Às vezes, nem mesmo posso dizer que elas estejam em desacordo com as minhas ideias. Não estou dizendo nada sobre suas crenças, muito menos sobre o que deveriam acreditar. Não tenho o conhecimento e, certamente, nem a autoridade (PANIKKAR, 1996, p. 269, tradução nossa). 
Essa seria, então, a base da atitude pluralista. Ou seja, o reconhecimento da própria ignorância com relação ao "Mistério" e de que não se pode "enxergar através de todas as janelas" ao mesmo tempo e, muito menos, controlá-las. Podemos, sim, "reconhecer a existência de outras janelas. [... ] ouvir e respeitar o discurso dos outros, entrar em diálogo com eles" (PANIKKAR, 1996, p. 247). Panikkar acredita que:

Não é erradicando todas as diferenças e impondo um esquema de inteligibilidade a priori, por mais perfeito que seja, que poderemos harmonizar a sinfonia das diversas civilizações do gênero humano, mas sim permitindo a todos aqueles que pertencem a essas diferentes civilizações a dizerem sua palavra, a dançar sua dança, a cantar seu canto, e procurando compreender o que todos querem dizer. [...] O pluralismo é uma exigência enraizada na natureza pluralista da realidade [...] começa através do reconhecimento da alteridade, a qual já implica a minha essência. Eu sou (estou) em relação (PANIKKAR, 2016b, p. 60-61, tradução nossa).

Trata-se do reconhecimento de que o humano é um ser plural, habita uma realidade plural, não conhece toda a verdade e o outro, constantemente, o interpela. E, ainda, há algo que está "além da compreensão" e que a todos desafia. Neste horizonte, aceitar a existência de "uma força transcendente" é, para Panikkar, a premissa para a existência de "uma sociedade pluralista". $\mathrm{Na}$ visão de Panikkar (1999), "o diálogo inter-religioso é um imperativo religioso e um dever histórico", mas só ocorre de maneira efetiva para seus participantes, quando acompanhado de um diálogo intra-religioso. Trata-se de um "efeito inevitável”, na medida em que se entra em contato com outra tradição através do diálogo, uma mudança na visão de mundo e na autocompreensão de sua própria religião. Para ele:

Podemos não convencer os parceiros; podemos até nos irritarmos com os outros; eles podem ser insensíveis às nossas opiniões. No entanto, nós, mesmo imperceptivelmente, modificamos nossa postura. O diálogo inter-religioso desencadeia o diálogo intrareligioso nas nossas mentes e corações (PANIKKAR, 1999, p. 141, tradução nossa). 
Estes diálogos acontecem porque a religiosidade, que perpassa o ser humano, o provoca a ser mais. Panikkar refere-se à essa dimensão religiosa como "aquela atitude do ser humano que é consciente de sua 'religação' com toda a Realidade, tanto a divina quanto a cósmica e a humana, e que se cristaliza em formas dependentes das culturas em que se vive" (PANIKKAR, 2005). Refere-se, portanto, ao sentido de relação de sua visão cosmoteândrica, pois "religa" o ser humano não somente a uma divindade, mas às três dimensões, que segundo ele, compõem a totalidade: Deus-Humano-Mundo. Nesse sentido, poder-se-ia dizer que a religiosidade é o próprio "vínculo", aquilo que conecta as três dimensões da realidade. "[...] o sentido da vida é chegar à plenitude [...] (à) realização da pessoa em sua tripla dimensão de corpo (cosmos), alma (humanidade) e espírito (divindade), participando na perichoresis de toda a realidade" (PANIKKAR; CARRARA, 2018, p. 70). O diálogo intra e inter-religiosos são possibilidades do emergir de novas perichoresis na contemporaneidade.

\section{Conclusão}

A noção advaita que permitiu a Panikkar experimentar a realidade cosmoteândrica e a (re)pensar a Trindade e a cristologia, sinaliza a importância de mantermos vivos os diálogos inter-religiosos e interculturais. Estes diálogos, além de provocar profundas experiências intra-religiosas - mergulho no interior da própria identidade - , estimulam a olhar a pluralidade que compõe e rodeia o humano. Sair de si, voltar a si e poder sair de novo mostra a dinamicidade do humano ao mesmo tempo em que o faz perceber a amplitude da realidade a qual pertence. Divino-Humano-Cosmos estão em constante relação adual e provocam sempre novas construções, para além de alguma espiritualidade ou tradição religiosa em particular.

Cristianismo, hinduísmo e budismo são tradições que possibilitam a humanidade a estar sempre relendo suas especificidades, ao mesmo tempo em que constroem novas alternativas. Trata-se de uma tríade religiosa numa vastidão 
de espiritualidades que compõem o mundo contemporâneo. Portanto, estar aberto ao diálogo, seja inter-religioso e/ou intercultural, é estar disposto a novas experiências e a novas (re)elaborações. A transformação de uma religião e de uma sociedade vem de iniciativas e de atitudes plurais, como bem demonstrou Panikkar. Quanto mais o diálogo estiver sendo estimulado, menores as chances de pensamentos e de atitudes fundamentalistas nos ambientes religiosos e sociais. Posturas dialógicas são apreendidas em convivências. Isto desafia as variadas instituições que lidam com seres humanos a se disponibilizarem a educar para o diálogo. Somente uma educação dialógica promoverá novos relacionamentos e novas construções conjuntas. Educar para o diálogo lança desafios aos Estados, instituições de ensino, instituições religiosas e de espiritualidades, OSC, famílias e comunidades. Trata-se de um convite aberto a todos os grupos sociais a se comprometerem, pois os resultados serão compartilhados pela humanidade.

\section{Referências}

AMALADOSS, M. "O pluralismo das religiões e o significado de Cristo". In: TEIXEIRA, F. (Org.). Diálogo de pássaros: nos caminhos do diálogo inter-religioso. São Paulo: Paulinas, 1993.

BAPTISTA, P. A. N. Libertação e ecologia: a teologia teoantropocósmica de Leonardo Boff. São Paulo: Paulinas, 2011. (Coleção Interfaces).

BOFF, L. Ecologia mundialização espiritualidade: a emergência de um novo paradigma. São Paulo: Ática, 1996.

BOFF, L. Humano assim como Jesus só Deus mesmo. In: Leonardo Boff.com, 2017. Disponível em: <https://leonardoboff.wordpress.com/2017/12/22/humano-assim-comojesus-so-deus-mesmo/> Acesso em: 6 mai. 2019.

COUSINS, E. H. Christ of the 21st century. New York: Continuuum, 1998.

D'SA, F. X. C. The Fullnesss of Man. Raimon Panikkar's Vision for the New Millennium. In: ACHARYA, K.; CARRARA PAVAN, M. (Eds.). Raimon Panikkar: His Legacy and Vision. 
Mumbai/Nova Deli: Somaiya, 2008a. p. 207-221. Disponível em: <http://www.isrpune.org/pdf/FXDSa_articles/2008_g\%20Christophany.\%20The\%20Fullne Sss_FXDSa_articles.pdf > Acesso em: 13 maio 2019.

D'SA, F. X. The advaita principle of Raimon Panikkar and Trinity. In: GNANAPRAGASAM, P.; SCHÜSSLER FIORENZA, E. (Eds.). Negotiating Borders: Theological Explorations in the Global Era. Essays in Honour of Prof. Felix Wilfred. Deli: ISPCK, 2008b. p. 158-166. Disponível em:

<http://www.isrpune.org/pdf/FXDSa_articles/2008_d\%20The\%20Advaita\%20Principle_FX DSa_articles.pdf> Acesso em: 21 maio 2019.

HAIGHT, R. Jesus, símbolo de Deus. São Paulo: Palinas, 2003.

KASPER, W. Jesús, el Cristo. Salamanca: Sígueme, 1984.

KNITTER, P. Introdução à teologia das religiões. São Paulo: Paulinas, 2009.

KOMULAINEN, J. Raimon Panikkar's cosmotheandrism: theologizing at the meeting point of Hinduism and Christianity. Exchange, Leiden, v. 35, n. 3, p. 278-303, 2006.

MENDONÇA, C. The major concepts of Raimon Panikkar. In: ACHARYA, K.; CARRARA, M. P. (Eds.). Raimon Panikkar, His Legacy and Vision. Mumbai: Somayya, 2008. p. 2334. Disponível em:

<http://www.isrpune.org/pdf/DrClemens_articles/2008_b_major\%20concept\%200f\%20p anikkar_DrClemens_articles.pdf >. Acesso em: 19 abr. $201 \overline{0}$.

MEZA RUEDA, J. L. El ser humano como realidad cosmoteándrica: una contribución de Raimon Panikkar frente al dualismo antropológico. Cuestiones Teológicas, Colômbia, v. 36, n. 85, p. 59-80, 2009. Disponível em:

<https://revistas.upb.edu.co/index.php/cuestiones/article/view/118>. Acesso em: 23 abr. 2019 .

MEZA RUEDA, J. L. De la cristología a la cristofanía. Dupuis y Panikkar en diálogo. Theologica Xaveriana, Colômbia, 2012, v. 62, n. 173, p. 115-136. Disponível em: <http://revistas.javeriana.edu.co/index.php/teoxaveriana/article/view/9338>. Acesso em: 1 set. 2019.

PANASIEWICZ, R. Pluralismo religioso contemporâneo: diálogo inter-religioso na teologia de Claude Geffré. 2. ed. São Paulo: Paulinas/Pucminas, 2010.

PANASIEWICZ, R. Teologia da criação: uma leitura da relação entre Criador e criaturas. In: OLIVEIRA, Pedro A. Ribeiro de; SOUZA, José Carlos Aguiar de (Orgs.). Consciência 
planetária e religião: desafios para o Século XXI. São Paulo: Paulinas, 2009. (Coleção estudos da religião).

PANIKKAR, R. Christianity: a christophany. New York: Orbis, 2016a. v. III.2. [Opera Omnia]

PANIKKAR, R. VI. Culturas y religiones en diálogo: 1. Pluralismo y interculturalidad. Barcelona: Herder, 2016b. [Obras completas].

PANIKKAR, R. El Cristo desconocido del hinduismo. Madrid: Grupo Libro 88, 1994.

PANIKKAR, R. Entre Dieu et le cosmos: Une vision non dualiste de la réalité. Paris: Albin Michel, 2012. (Entretiens avec Gewndoline Jarcyk).

PANIKKAR, R. Espiritualidad hindú. Barcelona: Kairós, 2005. [E-Book].

PANIKKAR, R. I. Mística y espiritualidad: 1. Mística, plenitud de vida. Barcelona: Herder, 2015. [Obras completas].

PANIKKAR, R. Myth, Faith and Hermeneutics: Cross-Cultural Studies. New York: Paulist Press, 1979.

PANIKKAR, R. A self-critical dialogue. In: PRABHU, J. (Org.). The intercultural challenge of Raimon Panikkar. New York: Orbis, 1996. p. 227-292.

PANIKKAR, R. The intrareligious dialogue. New Jersey: Paulist Press, 1999.

PANIKKAR, R. The rhythm of being: the Gifford lectures. New York: Orbis, 2013.

PANIKKAR, R. Visión trinitária y cosmoteándrica: dios-hombre-cosmos. Milão: Jaca Book, 2011. [E-Book].

PANIKKAR, R. VIII. Visión trinitária e cosmoteándrica: dios-hombre-cosmos. Barcelona: Herder, 2016c. [Obras completas].

PANIKKAR, R.; CARRARA, M. Peregrinación al Kailasa: y al centro de uno mismo. Barcelona: Luciérnaga, 2018.

PÉREZ PRIETO, V.Dios, Hombre, Mundo: la trinidad en Raimon Panikkar. Barcelona: Herder, 2008. [E-Book].

PIKAZA, X. Prólogo. In: PÉREZ PRIETO, V. Dios, Hombre, Mundo: la trinidad en Raimon Panikkar. Barcelona: Herder, 2008. [E-Book]. 
PRABHU, J. (Org.). The intercultural challenge of Raimon Panikkar. New York: Orbis, 1996.

SEGUNDO, J. L. Que mundo? Que homem? Que Deus?: aproximações entre ciência, filosofia e teologia. São Paulo: Paulinas, 1995.

TEIXEIRA, F. Teologia e pluralismo religioso. São Bernardo do Campo: Nhanduti, 2012.

VIGIL, J. M. Teologia do pluralismo religioso: para uma releitura pluralista do cristianismo. São Paulo: Paulus, 2006.

VON SINNER, R. Hermenêutica ecumênica para um cristianismo plural: reflexões sobre contextualidade e catolicidade. Estudos Teológicos, São Leopoldo, v. 44, n. 22, p. 26-57, 2004. Disponível em:

<http://www3.est.edu.br/publicacoes/estudos_teologicos/vol4402_2004/et20042rvsinner.pdf>. Acesso em: 19 abr. 2019.

RECEBIDO: 06/11/2019

APROVADO: 20/04/2020
RECEIVED: $11 / 06 / 2019$

APPROVED: 04/20/2020 